\title{
Best proximity point theorems for $\alpha$-nonexpansive mappings in Banach spaces
}

\author{
Dezhou Kong ${ }^{1,2}$, Lishan Liu ${ }^{1,3^{*}}$ and Yonghong $\mathrm{Wu}^{3,4}$
}

\section{"Correspondence:} mathlls@163.com

${ }^{1}$ School of Mathematical Sciences, Qufu Normal University, Qufu, Shandong 273165, People's Republic of China

${ }^{3}$ Department of Mathematics and Statistics, Curtin University, Perth, WA 6845, Australia

Full list of author information is available at the end of the article

\begin{abstract}
In this paper, we discuss sufficient and necessary conditions for the existence of best proximity points for non-self- $\alpha$-nonexpansive mappings in Banach spaces. We obtain convergence results under some assumptions, and we prove the existence of common best proximity points for a family of non-self- $\alpha$-nonexpansive mappings.
\end{abstract}

MSC: $90 \mathrm{C} 33 ; 54 \mathrm{H} 25 ; 47 \mathrm{H} 09 ; 34 \mathrm{~B} 18$

Keywords: best proximity point; common best proximity point; $\alpha$-nonexpansive; $d$-property

\section{Introduction}

Let $(X, d)$ be a metric space and $A$ a nonempty subset of $X$. The mapping $T: A \rightarrow X$ is said to have a fixed point in $A$ if the fixed point equation $T x=x$ has at least one solution. In metric terminology, we say that $x \in A$ is a fixed point of $T$ if $d(x, T x)=0$. If the fixed point equation of a given mapping does not have a solution, then $d(x, T x)>0$ for all $x \in A$. In such a situation, it is our aim to find an element $x \in A$ such that $d(x, T x)$ is minimum in some sense, and the $x$ is said to be the best approximation of the fixed point of $T$. In this paper, we will study the best approximation theory and best proximity pair theorems.

Consider the following well-known best approximation theorem due to Ky Fan [1].

Theorem 1.1 [1] Let A be a nonempty compact convex set in a normed linear space X. If $T$ is a continuous map from $A$ into $X$, then there exists a point $x$ in $A$ such that $\|x-T x\|=$ $\operatorname{dist}(T x, A)$.

The point $x$ in the theorem above is called a best approximation point of $T$ in $A$. Note that if $x \in A$ is a best approximation point, then $\|x-T x\|$ need not be the optimum. Best proximity point theorems have been explored to find sufficient conditions so that the minimization problem $\min _{x \in A}\|x-T x\|$ has at least one solution. To have a concrete lower bound, let us consider two nonempty subsets $A, B$ of a metric space $X$ and a mapping $T: A \rightarrow B$. The natural question is whether one can find an element $x_{0} \in A$ such that $d\left(x_{0}, T x_{0}\right)=\min \{d(x, T x): x \in A\}$. Since $d(x, T x) \geq \operatorname{dist}(A, B)$, it is of interest to find a point $x_{0} \in A$ such that $d\left(x_{0}, T x_{0}\right)=\operatorname{dist}(A, B)$. This situation motivates the researchers to develop the notion called best proximity point theory. It is worth to note that the best proximity point theorems can be viewed as a generalization of fixed point theorems, since most fixed

(c) 2015 Kong et al. This article is distributed under the terms of the Creative Commons Attribution 4.0 International License (http://creativecommons.org/licenses/by/4.0/), which permits unrestricted use, distribution, and reproduction in any medium, provided you give appropriate credit to the original author(s) and the source, provide a link to the Creative Commons license, and indicate if changes were made. 
point theorems can be derived as corollaries of best proximity point theorems. Some of the interesting results for best proximity points can be found in [2-18].

Let $A, B$ be two nonempty subsets of a normed linear space $X$. Let us fix the following notation which will be used throughout this article:

$$
\begin{aligned}
& A_{0}=\{x \in A:\|x-y\|=\operatorname{dist}(A, B) \text { for some } y \in B\}, \\
& B_{0}=\{y \in B:\|x-y\|=\operatorname{dist}(A, B) \text { for some } x \in A\} .
\end{aligned}
$$

The following notion of weakly contractive mapping was introduced by Sankar Raj in [19].

Definition 1.1 [19] Let $A, B$ be nonempty subsets of a metric space $(X, d)$. A map $T: A \rightarrow$ $B$ is said to be a weakly contractive mapping if

$$
d(T x, T y) \leq d(x, y)-\psi(d(x, y)), \quad \forall x, y \in A,
$$

where $\psi:[0, \infty) \rightarrow[0, \infty)$ is a continuous and nondecreasing function such that $\psi$ is positive $(0, \infty), \psi(0)=0$, and $\lim _{t \rightarrow \infty} \psi(t)=\infty$. If $A$ is bounded, then $\lim _{t \rightarrow \infty} \psi(t)=\infty$ can be omitted.

Note that $d(T x, T y) \leq d(x, y)-\psi(d(x, y))<d(x, y)$ if $x, y \in A$ with $x \neq y$. That is, $T$ is a contractive map. In [19], Sankar Raj obtained the existence theorem of a best proximity point for weakly contractive mappings as follows.

Theorem 1.2 [19] Let $(A, B)$ be a pair of two nonempty closed subsets of a complete metric space $X$ such that $A_{0}$ is nonempty. Let $T: A \rightarrow B$ be a weakly contractive mapping such that $T\left(A_{0}\right) \subseteq B_{0}$. Assume that the pair $(A, B)$ has the $d$-property. Then there exists a unique point $x^{*}$ in $A$ such that $d\left(x^{*}, T x^{*}\right)=\operatorname{dist}(A, B)$.

In [20], Aoyama and Kohsaka introduced the self- $\alpha$-nonexpansive mapping which is defined as follows.

Definition 1.2 [20] Let $X$ be a Banach space, let $A$ be a nonempty subset of $X$, and let $\alpha$ be a real number such that $\alpha<1$. A mapping $T: A \rightarrow A$ is said to be $\alpha$-nonexpansive if

$$
\|T x-T y\|^{2} \leq \alpha\|T x-y\|^{2}+\alpha\|T y-x\|^{2}+(1-2 \alpha)\|x-y\|^{2}
$$

for all $x, y \in A$.

It is obvious that every nonexpansive mapping is 0-nonexpansive. We denote the fixed point set of a mapping $T$ by $F(T)$. In [20], they proved the following result.

Theorem 1.3 [20] Let X be a uniformly convex Banach space, let A be a nonempty, closed, and convex subset of $X$, and let $T: A \rightarrow A$ be an $\alpha$-nonexpansive mapping for some real number $\alpha$ such that $\alpha<1$. Then $F(T)$ is nonempty if and only if there exists $x \in A$ such that $\left\{T^{n}(x)\right\}$ is bounded. 
In [21] and [22], Abkar and Gabeleh studied the best proximity points of some non-selfmappings under appropriate conditions.

Motivated and inspired by the above mentioned work, in this article, we consider a map $T: A \rightarrow B$, where $A$ and $B$ are nonempty subsets of a Banach space $X$, which is non-self$\alpha$-nonexpansive in the sense of Definition 1.2. We attempt to study the sufficient and necessary conditions for the existence of a best proximity point for non-self- $\alpha$-nonexpansive mappings and convergence results. Moreover, we discuss the existence of common best proximity points for a family of non-self- $\alpha$-nonexpansive mappings. When the map $T$ is considered to be a self-map, then our result reduces to the fixed point theorem of Aoyama and Kohsaka for $\alpha$-nonexpansive mappings. Our results are generalization and improvement of the recent results obtained by many authors.

\section{Preliminaries}

Let $X$ be a normed linear space and $C$ be a nonempty subset of $X$. Then the metric projection operator $P_{C}: X \rightarrow C$ is defined by

$$
P_{C}(x)=\{y \in C:\|x-y\|=\operatorname{dist}(x, C)\} \quad \text { for all } x \in X .
$$

It is well known that, if $C$ is assumed to be a closed and convex subset of a strictly convex and reflexive Banach space $X$, then $P_{C}(x)$ is nonempty and single valued for all $x \in X$.

In [23], Kirk et al. proved the following lemma which guarantees the nonemptiness of $A_{0}$ and $B_{0}$.

Lemma 2.1 [23] Let $X$ be a reflexive Banach space and A be a nonempty, closed, bounded, and convex subset of $X$, and $B$ be a nonempty, closed, and convex subset of $X$. Then $A_{0}$ and $B_{0}$ are nonempty and satisfy $P_{B}\left(A_{0}\right) \subseteq B_{0}, P_{A}\left(B_{0}\right) \subseteq A_{0}$.

Also, in [24], Sadiq Basha and Veeramani proved that $A_{0}$ is contained in the boundary of $A$. It is easy to verify that $A_{0}$ and $B_{0}$ are closed convex subsets of $A$ and $B$, respectively, if $A$ and $B$ are closed and convex.

The notion called the $d$-property was introduced in [25].

Definition 2.1 [25] A pair $(A, B)$ of nonempty subsets of a normed linear space $X$ is said to have the $d$-property if and only if

$$
\left.\begin{array}{l}
\left\|x_{1}-y_{1}\right\|=\operatorname{dist}(A, B), \\
\left\|x_{2}-y_{2}\right\|=\operatorname{dist}(A, B)
\end{array}\right\} \quad \Rightarrow \quad\left\|x_{1}-x_{2}\right\|=\left\|y_{1}-y_{2}\right\|,
$$

whenever $x_{1}, x_{2} \in A$ and $y_{1}, y_{2} \in B$.

Definition 2.2 [25] A normed linear space $X$ is said to have the $d$-property if and only if every pair $(A, B)$ of nonempty and closed convex subsets of $X$ has the $d$-property.

Lemma 2.2 [25] $X$ is strictly convex if and only if $X$ has the d-property.

Lemma 2.3 [25] Let $A, B$ be nonempty, closed, and convex subsets of a strictly convex space $X$ such that $A_{0}$ is nonempty. Then the restriction of the metric projection mapping $P_{A_{0}}$ to $B_{0}$ is an isometry. That is, $P_{A_{0}}: B_{0} \rightarrow A_{0}$ is an isometry. 
Let $A, B$ be nonempty, closed, and convex subsets of a strictly convex space $\mathrm{X}$ such that $A_{0}$ is nonempty. Consider the mapping $P: A \cup B \rightarrow A \cup B$ defined by

$$
P(x)= \begin{cases}P_{B}(x), & \text { if } x \in A \\ P_{A}(x), & \text { if } x \in B\end{cases}
$$

Let us define the notion of non-self- $\alpha$-nonexpansive maps as follows.

Definition 2.3 Let $A, B$ be nonempty subsets of a Banach space $X$ and $\alpha$ a real number such that $\alpha<1$. A map $T: A \rightarrow B$ is said to be an $\alpha$-nonexpansive mapping if

$$
\|T x-T y\|^{2} \leq \alpha\|T x-P y\|^{2}+\alpha\|T y-P x\|^{2}+(1-2 \alpha)\|x-y\|^{2}
$$

for all $x, y \in A$.

Remark 2.1 We note that a non-self-nonexpansive mapping $(\|T x-T y\| \leq\|x-y\|, x, y \in A)$ $T: A \rightarrow B$ is a non-self-0-nonexpansive mapping.

The following example shows that there is a discontinuous non-self- $\alpha$-nonexpansive mapping.

Example 2.1 Let $X$ be a uniformly convex Banach space, $A=\left\{x \in X:\left\|x-x_{0}\right\| \leq 2\right\}, B=$ $\{x \in X:\|x\| \leq 1\}$, where $\left\|x_{0}\right\| \geq 3$. Let $\alpha$ and $\gamma$ be real numbers such that $\frac{1}{2} \leq \alpha<1$ and $0<\gamma \leq \frac{1}{2}$. Then the mapping $F: A \rightarrow B$ defined by

$$
F(x)= \begin{cases}\gamma P_{B}(x), & \text { if } x \in A_{0} \\ 0, & \text { if } x \in A / A_{0}\end{cases}
$$

is non-self- $\alpha$-nonexpansive and discontinuous.

Proof Since $X$ is a uniformly convex Banach space and $A, B$ are bounded closed convex subsets of $X$, we know that $B_{0}$ is a nonempty, closed, and convex subset in the boundary set of $B$ and $P_{B}(x)=P_{B_{0}}(x)$, for all $x \in A_{0}$. For any $x, y \in A_{0}$, by Lemma 2.3 , we have

$$
\begin{aligned}
\|F(x)-F(y)\|^{2}= & \left\|\gamma P_{B}(x)-\gamma P_{B}(y)\right\|^{2} \leq\left\|P_{B_{0}}(x)-P_{B_{0}}(y)\right\|^{2} \\
= & \alpha\left\|P_{B_{0}}(x)-P_{B_{0}}(y)\right\|^{2}+\alpha\left\|P_{B_{0}}(x)-P_{B_{0}}(y)\right\|^{2} \\
& +(1-2 \alpha)\left\|P_{B_{0}}(x)-P_{B_{0}}(y)\right\|^{2} \\
= & \alpha\left\|P_{B_{0}}(x)-P_{B_{0}}(y)\right\|^{2}+\alpha\left\|P_{B_{0}}(x)-P_{B_{0}}(y)\right\|^{2}+(1-2 \alpha)\|x-y\|^{2} \\
= & \alpha\left\|F(x)-P_{B_{0}}(y)\right\|^{2}+\alpha\left\|P_{B_{0}}(x)-F(y)\right\|^{2}+(1-2 \alpha)\|x-y\|^{2} .
\end{aligned}
$$

Thus, in the case when either $x, y \in A_{0}$ or $x, y \in A / A_{0}$, we obviously have

$$
\|F(x)-F(y)\|^{2} \leq \alpha\|F(x)-P(y)\|^{2}+\alpha\|P(x)-F(y)\|^{2}+(1-2 \alpha)\|x-y\|^{2} .
$$

In the case when $x \in A_{0}$ and $y \in A / A_{0}$, we have

$$
\begin{gathered}
\alpha\|F(x)-P(y)\|^{2}+\alpha\|P(x)-F(y)\|^{2}+(1-2 \alpha)\|x-y\|^{2} \\
\geq \alpha\|P(x)-F(y)\|^{2}=\alpha\|P(x)\|^{2}=\alpha\left\|P_{B_{0}}(x)\right\|^{2}=\alpha
\end{gathered}
$$


and

$$
\|F(x)-F(y)\|^{2}=\|F(x)-F(y)\|^{2}=\left\|\gamma P_{B}(x)\right\|^{2}=\gamma^{2}\left\|P_{B_{0}}(x)\right\|^{2}=\gamma^{2} .
$$

Then $F$ is $\alpha$-nonexpansive.

Lemma 2.4 Let $A, B$ be nonempty, closed, and convex subsets of a strictly convex space $X$ such that $A_{0}$ is nonempty. Then $P^{2}(x)=x$ for all $x \in A_{0} \cup B_{0}$.

Proof For any $x \in A_{0}$, we have

$$
\left\|x-P_{B_{0}}(x)\right\|=\operatorname{dist}(A, B) .
$$

From the above equality, we can obtain $x=P_{A_{0}} P_{B_{0}}(x)$, that is, $P^{2}(x)=x$. Similarly, we have $P^{2}(x)=x$ for all $x \in B_{0}$.

Remark 2.2 We note that there exists $x \in A_{0}$ such that $\|x-T(x)\|=\operatorname{dist}(A, B)$ if and only if $x$ is the fixed point of $P_{A_{0}} T$.

\section{Best proximity point theorems}

Now let us use the above characterization of strictly convex spaces to prove the following best proximity point theorem of non-self- $\alpha$-nonexpansive mappings.

Theorem 3.1 Let $X$ be a uniformly convex Banach space and $A, B$ be nonempty, closed, and convex subsets of $X$. Suppose that $A_{0}$ is nonempty and $T: A \rightarrow B$ is an $\alpha$-nonexpansive mapping on $A_{0}$ for some real number $\alpha$ such that $0<\alpha<1$ and $T\left(A_{0}\right) \subseteq B_{0}$. Then $T$ has at least one best proximity point if and only if there exists $x \in A_{0}$ such that $\left\{(P T)^{n}(x)\right\}$ is bounded. Moreover, if $T$ is continuous and $\left\|(P T)^{2}(x)-x\right\| \leq r\|(P T)(x)-x\|$ for all $x \in A_{0}$, where $0<r<\sqrt{2}$, then $(P T)^{n}(x)$ converges to a proximity point for all $x \in A_{0}$.

Proof First we remark that $P(x)=P_{B_{0}}(x), P(y)=P_{B_{0}}(y)$ for any $x \in A_{0}, y \in B_{0}$. Let us consider the mapping $P T: A \rightarrow A$ on $A_{0}$, i.e. $P_{A_{0}} T: A_{0} \rightarrow A_{0}$. Since $T: A \rightarrow B$ is an $\alpha$-nonexpansive mapping, by Lemmas 2.3 and 2.4, for all $x, y \in A_{0}$, we have

$$
\begin{aligned}
& \|(P T)(x)-(P T)(y)\|^{2} \\
& \quad=\|T(x)-T(y)\|^{2} \\
& \quad \leq \alpha\|T(x)-P(y)\|^{2}+\alpha\|T(y)-P(x)\|^{2}+(1-2 \alpha)\|x-y\|^{2} \\
& \quad=\alpha\left\|\left(P^{2} T\right)(x)-P(y)\right\|^{2}+\alpha\left\|\left(P^{2} T\right)(y)-P(x)\right\|^{2}+(1-2 \alpha)\|x-y\|^{2} \\
& \quad=\alpha\|(P T)(x)-y\|^{2}+\alpha\|(P T)(y)-x\|^{2}+(1-2 \alpha)\|x-y\|^{2} .
\end{aligned}
$$

Thus $P_{A_{0}} T: A_{0} \rightarrow A_{0}$ is $\alpha$-nonexpansive. By Theorem 1.3, we see that $F\left(P_{A_{0}} T\right)$ is nonempty if and only if there exists $x \in A_{0}$ such that $\left\{\left(P_{A_{0}} T\right)^{n}(x)\right\}$ is bounded. Then $T$ has at least one best proximity point if and only if there exists $x \in A_{0}$ such that $\left\{(P T)^{n}(x)\right\}$ is bounded. 
Since $\left\|(P T)^{2}(x)-x\right\| \leq \sqrt{2}\|(P T)(x)-x\|$ for all $x \in A_{0}$ and $T$ is $\alpha$-nonexpansive, we have

$$
\begin{aligned}
&\left\|(P T)^{n+1}(x)-(P T)^{n}(x)\right\|^{2} \\
&=\left\|T(P T)^{n}(x)-T(P T)^{n-1}(x)\right\|^{2} \\
& \leq \alpha\left\|T(P T)^{n}(x)-P(P T)^{n-1}(x)\right\|^{2}+\alpha\left\|P(P T)^{n}(x)-T(P T)^{n-1}(x)\right\|^{2} \\
& \quad+(1-2 \alpha)\left\|(P T)^{n}(x)-(P T)^{n-1}(x)\right\|^{2} \\
&=\alpha\left\|(P T)^{n+1}(x)-(P T)^{n-1}(x)\right\|^{2}+\alpha\left\|(P T)^{n}(x)-(P T)^{n}(x)\right\|^{2} \\
& \quad+(1-2 \alpha)\left\|(P T)^{n}(x)-(P T)^{n-1}(x)\right\|^{2} \\
&=\alpha\left\|(P T)^{n+1}(x)-(P T)^{n-1}(x)\right\|^{2}+(1-2 \alpha)\left\|(P T)^{n}(x)-(P T)^{n-1}(x)\right\|^{2} \\
& \leq r^{2} \alpha\left\|(P T)^{n}(x)-(P T)^{n-1}(x)\right\|^{2}+(1-2 \alpha)\left\|(P T)^{n}(x)-(P T)^{n-1}(x)\right\|^{2} \\
&= {\left[1-\left(2-r^{2}\right) \alpha\right]\left\|(P T)^{n}(x)-(P T)^{n-1}(x)\right\|^{2} } \\
& \leq {\left[1-\left(2-r^{2}\right) \alpha\right]^{2}\left\|(P T)^{n-1}(x)-(P T)^{n-2}(x)\right\|^{2} } \\
& \leq \cdots \leq\left[1-\left(2-r^{2}\right) \alpha\right]^{n}\|(P T)(x)-x\|^{2} .
\end{aligned}
$$

Consequently, since $1-\left(2-r^{2}\right) \alpha<1$, one has

$$
\left\|(P T)^{n+p}(x)-(P T)^{n}(x)\right\|^{2} \leq \frac{\left[1-\left(2-r^{2}\right) \alpha\right]^{n}}{\left(2-r^{2}\right) \alpha}\|(P T)(x)-x\|^{2} .
$$

Thus $\left\{(P T)^{n}(x)\right\}$ is a Cauchy sequence in $A_{0}$, and hence there exists $x^{*} \in A_{0}$ such that $\left\{(P T)^{n}(x)\right\} \rightarrow x^{*}$ for $n \rightarrow \infty$. Since $T$ is continuous, we have $T(P T)^{n-1}(x) \rightarrow T\left(x^{*}\right)$. Thus

$$
\left\|T\left(x^{*}\right)-x^{*}\right\|=\lim _{n \rightarrow \infty}\left\|T(P T)^{n-1}(x)-(P T)^{n}(x)\right\|=\operatorname{dist}(A, B) .
$$

The assertion is proved.

Remark 3.1 If $A=B$, Theorem 3.1 is the fixed point theorem of Aoyamma and Kohsaka [20] with convergence result.

Remark 3.2 If $T$ is a weakly contractive mapping, by Theorem 3.1, we can obtain the best proximity point theorem of Sankar Raj [19] with convergence result.

Corollary 3.1 Let $X$ be a uniformly convex Banach space and $A, B$ be nonempty, closed, and convex subsets of $X$. Suppose that $A$ is bounded and $T: A \rightarrow B$ is an $\alpha$-nonexpansive mapping for some real number $\alpha<1$ such that $T\left(A_{0}\right) \subseteq B_{0}$. Then $T$ has at least one best proximity point.

Proof Since $X$ is a uniformly convex Banach space and $A$ is bounded, we see that $A_{0}$ is nonempty and $\left\{(P T)^{n}(x)\right\}$ is bounded for any $x \in A_{0}$. By Theorem 3.1, $T$ has at least one best proximity point.

Corollary 3.2 Let $X$ be a uniformly convex Banach space and $A, B$ be nonempty, closed, and convex subsets of $X$, and let $A_{0}$ be nonempty. Suppose that $T\left(A_{0}\right) \subseteq B_{0}$ and $T: A \rightarrow B$ 
is a nonexpansive mapping on $A_{0}$, i.e. $\|T(x)-T(y)\| \leq\|x-y\|$, for all $x, y \in A_{0}$. Then $T$ has at least one best proximity point if and only if there exists $x \in A_{0}$ such that $\left\{(P T)^{n}(x)\right\}$ is bounded.

Proof It is well known that nonexpansive mappings are 0-nonexpansive. By Theorem 3.1, the assertion is proved.

Let $A, B$ be nonempty convex subsets of a normed linear space. A mapping $T: A \rightarrow B$ is said to be affine if $T(\lambda x+(1-\lambda) y)=\lambda T(x)+(1-\lambda) T(y)$, for all $x, y \in A$ and $\lambda \in(0,1)$. For convenience, we define $F_{A}(T)=\{x \in A:\|x-T(x)\|=\operatorname{dist}(A, B)\}$.

Theorem 3.2 Let $X$ be a uniformly convex Banach space and $A, B$ be nonempty, closed, and convex subsets of $X$. Suppose that $A_{0}$ is nonempty, bounded and $T: A \rightarrow B, S: A \rightarrow A$ satisfy the following conditions:

(i) $T, S$ are, respectively, non-self- $\alpha$-nonexpansive and $\beta$-nonexpansive mappings on $A_{0}$ such that $\alpha, \beta<1$;

(ii) $T$ is an affine and continuous mapping, and $T\left(A_{0}\right) \subseteq B_{0}$;

(iii) $P_{B_{0}} S(x)=T S(x)$ for all $x \in F_{A}(T)$.

Then there exists at least one point $x^{*} \in A_{0}$ such that $\left\|S\left(x^{*}\right)-T\left(x^{*}\right)\right\|=\operatorname{dist}(A, B)$.

Proof Since $A_{0}$ is bounded, by Theorem 3.1, we see that $F_{A}(T) \subseteq A_{0}$ is nonempty. Assume that $\left\{x_{n}\right\} \in F_{A}(T)$ and $x_{n} \rightarrow x$ for $n \rightarrow \infty$, then $\left\|x_{n}-T\left(x_{n}\right)\right\|=\operatorname{dist}(A, B)$. Since $T$ is continuous, we have $\|x-T(x)\|=\operatorname{dist}(A, B)$. Therefore, $x \in F_{A}(T)$ and $F_{A}(T)$ is closed. As $T$ is affine, take $x, y \in F_{A}(T)$ and $\lambda \in(0,1)$, we have

$$
\begin{aligned}
& \|\lambda x+(1-\lambda) y-T(\lambda x+(1-\lambda) y)\| \\
& \quad=\|\lambda(x-T(x))+(1-\lambda)(y-T(y))\| \\
& \quad \leq \lambda\|x-T(x)\|+(1-\lambda)\|y-T(y)\|=\operatorname{dist}(A, B) .
\end{aligned}
$$

Thus $F_{A}(T)$ is convex. Now we consider $S$ on $F_{A}(T)$. Take any $x \in F_{A}(T)$, by (iii), we have

$$
\|S(x)-T S(x)\|=\operatorname{dist}(A, B) .
$$

Hence $S$ restricted to $F_{A}(T)$ is a self-map. That is $S: F_{A}(T) \rightarrow F_{A}(T)$. By Theorem 1.3, there exists $x^{*} \in F_{A}(T)$ such that $x^{*}=S\left(x^{*}\right)$. Furthermore, $\left\|S\left(x^{*}\right)-T\left(x^{*}\right)\right\|=\operatorname{dist}(A, B)$.

Remark 3.3 In Theorem 3.2, $S$ does not need to be continuous.

Example 3.1 Consider the uniformly convex space $\left(\mathbb{R}^{2},\|\cdot\|_{2}\right)$. Let

$$
\begin{aligned}
& A=\{(x, y): 0 \leq x \leq 1,0 \leq y \leq 1\} \quad \text { and } \\
& B=\{(x, y): 2 \leq x \leq 4,0 \leq y \leq 1\} .
\end{aligned}
$$

Then $A$ and $B$ are nonempty, closed, bounded, and convex subsets of $\mathbb{R}^{2}$ with $\operatorname{dist}(A, B)=1$. It is easy to verify that $A_{0}=\{(1, y): 0 \leq y \leq 1\}$ and $B_{0}=\{(2, y): 0 \leq y \leq 1\}$. Define a map 
$T: A \rightarrow B$ by $T(x, y)=(x+1, y)$ for all $(x, y) \in A$. Clearly, $T\left(A_{0}\right) \subseteq B_{0}$ and $T$ is an $\alpha$ nonexpansive mapping for any $\alpha<1$. Define a map $S: A \rightarrow A$ by $S(x, y)=\left(x, \frac{1}{2} y^{2}\right)$ for all $(x, y) \in A$. It is easy to prove that $S$ is $\frac{1}{2}$-nonexpansive on $A_{0}$ and $P_{B_{0}} S(x)=T S(x)$ for all $x \in A_{0}$. Note that $x^{*}=(1,0)$ satisfies $\left\|S\left(x^{*}\right)-T\left(x^{*}\right)\right\|=\operatorname{dist}(A, B)$.

\section{Common best proximity points}

In this section, we discuss sufficient conditions for the existence of common best proximity points for $\alpha$-nonexpansive mappings.

Theorem 4.1 Let $X$ be a uniformly convex Banach space and $A, B$ be nonempty, closed, and convex subsets of $X$. Suppose that $A_{0}$ is nonempty and bounded, and $T: A \rightarrow B$ and $S: A \rightarrow B$ satisfy the following conditions:

(i) $T, S$ are respectively $\alpha$-nonexpansive and $\beta$-nonexpansive mappings on $A_{0}$ such that $\alpha, \beta<1$;

(ii) $T$ is an affine and continuous mapping, and $T\left(A_{0}\right) \subseteq B_{0}, S\left(A_{0}\right) \subseteq B_{0}$;

(iii) for any $x \in F_{A}(T)$, there exists $y \in F_{A}(T)$ such that $S(x)=T(y)$.

Then there exists at least one point $x^{*} \in A_{0}$ such that $\left\|x^{*}-S\left(x^{*}\right)\right\|=\operatorname{dist}(A, B)$ and $\| x^{*}-$ $T\left(x^{*}\right) \|=\operatorname{dist}(A, B)$.

Proof From the proof of Theorem 3.2, we know that $F_{A}(T)$ is a nonempty, closed, and convex subset of $A_{0}$. Now we consider $S: A \rightarrow B$ on $F_{A}(T)$. Take any $x \in F_{A}(T)$, by (iii), we have

$$
\|y-S(x)\|=\|y-T(y)\|=\operatorname{dist}(A, B) .
$$

Thus

$$
\left\|S(x)-P_{F_{A}(T)}(S(x))\right\| \leq\|y-S(x)\|=\operatorname{dist}(A, B) .
$$

Therefore, $P_{F_{A}(T)}(S(x))=P_{A_{0}}(S(x))$ for all $x \in F_{A}(T)$. Hence $S$ is a $\beta$-nonexpansive mapping on $F_{A}(T)$. By Theorem 3.1, there exists at least one point $x^{*} \in F_{A}(T)$ such that $\left\|x^{*}-S\left(x^{*}\right)\right\|=$ $\operatorname{dist}(A, B)$. The assertion is proved.

The following theorem guarantees the existence of a common best proximity point for a finite family $\mathfrak{\Im}=\left\{T_{1}, T_{2}, \ldots, T_{n}\right\}$ of affine, $\alpha$-nonexpansive mappings.

Theorem 4.2 Let $X$ be a uniformly convex Banach space and $A, B$ be nonempty, closed, and convex subsets of $X$. Suppose that $A_{0}$ is nonempty and bounded and $\Im=\left\{T_{1}, T_{2}, \ldots, T_{n}\right\}$ is a family mappings, where $T_{i}: A \rightarrow B(i=1,2, \ldots, n)$ satisfy the following conditions:

(i) $T_{i}$ are respectively $\alpha_{i}$-nonexpansive mappings on $A_{0}$ such that $\alpha_{i}<1$, for all $i=1,2, \ldots, n$;

(ii) $T_{i}$ are an affine and continuous mappings, and $T_{i}\left(A_{0}\right) \subseteq B_{0}$ for all $i=1,2, \ldots, n$;

(iii) for any $x \in \bigcap_{k=1}^{i-1} F_{A}\left(T_{k}\right)$, there exists $y \in \bigcap_{k=1}^{i-1} F_{A}\left(T_{k}\right)$ such that $T_{i}(x)=T_{1}(y)$ for all $i=1,2, \ldots, n$.

Then there exists at least one point $x^{*} \in A_{0}$ such that $\left\|x^{*}-T_{i}\left(x^{*}\right)\right\|=\operatorname{dist}(A, B)$ for all $i=$ $1,2, \ldots, n$. 
Proof From the proof of Theorem 3.2, we know that $F_{A}\left(T_{i}\right)$ is a nonempty, closed, and convex subset of $A_{0}$ for all $i=1,2, \ldots, n$. Theorem 4.1 implies that $F_{A}\left(T_{1}\right) \cap F_{A}\left(T_{2}\right)$ is a nonempty, closed, and convex set. Following a similar argument as Theorem 4.1, we can prove that $T_{3}$ on $F_{A}\left(T_{1}\right) \cap F_{A}\left(T_{2}\right)$ is an $\alpha_{3}$-nonexpansive mapping. Thus there exists a best proximity point $z^{*} \in F_{A}\left(T_{1}\right) \cap F_{A}\left(T_{2}\right)$. By repeating the argument, we can prove that there exists $x^{*} \in \bigcap_{i=1}^{n} F_{A}\left(T_{i}\right)$ such that $\left\|x^{*}-T_{i}\left(x^{*}\right)\right\|=\operatorname{dist}(A, B)$ for all $i=1,2, \ldots, n$.

Example 4.1 Consider the uniformly convex space $\left(\mathbb{R}^{2},\|\cdot\|_{2}\right)$. Let

$$
\begin{aligned}
& A=\{(x, y): 0 \leq x \leq 1,0 \leq y \leq 1\}, \\
& B=\{(x, y): 2 \leq x \leq 4,0 \leq y \leq 1\} .
\end{aligned}
$$

Then $A$ and $B$ are nonempty, closed, bounded, and convex subsets of $\mathbb{R}^{2}$ with $\operatorname{dist}(A, B)=1$. It is easy to verify that $A_{0}=\{(1, y): 0 \leq y \leq 1\}$ and $B_{0}=\{(2, y): 0 \leq y \leq 1\}$. Define a map $T: A \rightarrow B$ by $T(x, y)=(x+1, y)$ for all $(x, y) \in A$. Clearly, $T\left(A_{0}\right) \subseteq B_{0}$ and $T$ is an $\alpha$-nonexpansive mapping for any $\alpha<1$. Define a map $S: A \rightarrow B$ by

$$
S(x)= \begin{cases}\left(x+1, \frac{1}{2} y^{2}\right), & \text { if }(x, y) \in\left\{(x, y):(x, y) \in A_{0} \text { such that } y \geq \frac{1}{2}\right\} \\ (3 x-1, y), & \text { if }(x, y) \in\left\{(x, y):(x, y) \in A_{0} \text { such that } y<\frac{1}{2}\right\} \\ (2 x+2, y), & \text { if }(x, y) \in A / A_{0} .\end{cases}
$$

It is easy to prove $S$ is $\frac{1}{2}$-nonexpansive on $A_{0}$. Note that $x^{*} \in\left\{(x, y):(x, y) \in A_{0}\right.$ such that $y<$ $\left.\frac{1}{2}\right\}$ satisfies $\left\|x^{*}-S\left(x^{*}\right)\right\|=\operatorname{dist}(A, B)$ and $\left\|x^{*}-T\left(x^{*}\right)\right\|=\operatorname{dist}(A, B)$.

\section{Competing interests}

The authors declare that they have no competing interests.

\section{Authors' contributions}

All authors read and approved the final manuscript.

\section{Author details}

${ }^{1}$ School of Mathematical Sciences, Qufu Normal University, Qufu, Shandong 273165, People's Republic of China. ${ }^{2}$ College of Information Science and Engineering, Shandong Agricultural University, Taian, Shandong 271018, People's Republic of China. ${ }^{3}$ Department of Mathematics and Statistics, Curtin University, Perth, WA 6845, Australia. ${ }^{4}$ School of Statistics and Mathematics, Zhongnan University of Economics and Law, Wuhan, 430073, People's Republic of China.

\section{Acknowledgements}

The first and second authors were supported financially by the National Natural Science Foundation of China (11371221) the Specialized Research Foundation for the Doctoral Program of Higher Education of China (20123705110001) and the Program for Scientific Research Innovation Team in Colleges and Universities of Shandong Province. The third author was supported financially by the Australia Research Council through an ARC Discovery Project Grant.

Received: 25 January 2015 Accepted: 24 June 2015 Published online: 04 September 2015

\section{References}

1. Fan, K: A generalization of Tychonoff's fixed point theorem. Math. Ann. 142, 305-310 (1961)

2. Eldred, AA, Veeramani, P: Existence and convergence of best proximity points. J. Math. Anal. Appl. 323(2), 1001-1006 (2006)

3. Eldred, AA, Sankar Raj, V, Veeramani, P: On best proximity pair theorems for relatively u-continuous mappings. Nonlinear Anal. 74, 3870-3875 (2011)

4. Kirk, WA: A fixed point theorem for mappings which do not increase distances. Am. Math. Mon. 72, 1004-1006 (1965)

5. Jeli, M, Samet, B: Remarks on the paper: Best proximity point theorems: an exploration of a common solution to approximation and optimization problems. Appl. Math. Comput. 228, 366-370 (2014)

6. Haghi, RH, Rakočević, V, Rezapour, S, Shahzad, N: Best proximity results in regular cone metric spaces. Rend. Circ. Mat. Palermo 60, 323-327 (2011)

7. Sadiq Basha, S: Common best proximity points: global minimal solutions. Top 21, 182-188 (2013)

8. Shahzad, N, Sadiq Basha, S, Jeyaraj, R: Common best proximity points: global optimal solutions. J. Optim. Theory Appl. 148(1), 69-78 (2011) 
9. Suzuki, T, Kikkawa, M, Vetro, C: The existence of best proximity points in metric spaces with the property UC. Nonlinear Anal. 71(7-8), 2918-2926 (2009)

10. Al-Thagafi, MA, Shahzad, N: Convergence and existence results for best proximity points. Nonlinear Anal. 70, 3665-3671 (2009)

11. Amini-Harandi, A: Best proximity points for proximal generalized contractions in metric spaces. Optim. Lett. 7, 913-921 (2013)

12. Kim, WK, Kum, S, Lee, KH: On general best proximity pairs and equilibrium pairs in free abstract economies. Nonlinear Anal. 68(8), 2216-2227 (2008)

13. Samet, B: Some results on best proximity points. J. Optim. Theory Appl. 159, 281-291 (2013)

14. Chen, CM: A note on asymptotic pointwise weaker Meir-Keeler-type contractions. Appl. Math. Lett. 25(10), 1267-1269 (2012)

15. Sintunavarat, W, Cho, YJ, Kumam, P: Common fixed point theorems for c-distance in ordered cone metric spaces. Comput. Math. Appl. 62, 1969-1978 (2011)

16. Sadiq Basha, S: Best proximity point theorems: an exploration of a common solution to approximation and optimization problems. Appl. Math. Comput. 218, 9773-9780 (2012)

17. Abkar, A, Gabeleh, M: Best proximity points for cyclic mappings in ordered metric spaces. J. Optim. Theory Appl. 151, 418-424 (2011)

18. Karapinar, E, Petrusel, G, Tas, K: Best proximity point theorems for KT-types cyclic orbital contraction mappings. Fixed Point Theory 13, 537-546 (2012)

19. Sankar Raj, V: A best proximity point theorem for weakly contractive non-self mappings. Nonlinear Anal. 74 4804-4808 (2011)

20. Aoyama, K, Kohsaka, F: Fixed point theorem for $\alpha$-nonexpansive mappings in Banach spaces. Nonlinear Anal. 74 4387-4391 (2011)

21. Abkar, A, Gabeleh, M: Best proximity points of non-self mappings. Top 21, 287-295 (2013)

22. Abkar, A, Gabeleh, M: A best proximity point theorem for Suzuki type contraction non-self mappings. Fixed Point Theory 14(2), 281-288 (2013)

23. Kirk, WA, Reich, S, Veeramani, P: Proximinal retracts and best proximity pair theorems. Numer. Funct. Anal. Optim. 24(7-8), 851-862 (2003)

24. Sadiq Basha, S, Veeramani, P: Best proximity pair theorems for multifunctions with open fibres. J. Approx. Theory 103(1), 119-129 (2000)

25. Sankar Raj, V, Eldred, AA: A characterization of strictly convex spaces and applications. J. Optim. Theory Appl. 160 703-710 (2014)

\section{Submit your manuscript to a SpringerOpen ${ }^{\circ}$ journal and benefit from:}

- Convenient online submission

Rigorous peer review

- Immediate publication on acceptance

Open access: articles freely available online

- High visibility within the field

- Retaining the copyright to your article 